\title{
Living without microphysical supervenience
}

\author{
Alex Moran, University of Oxford ${ }^{\mathrm{I}}$
}

This is a revised version of a paper published in Philosophical Studies.

\begin{abstract}
The Doctrine of Microphysical Supervenience states that microphysical duplicates cannot differ in their intrinsic properties. According to Merricks (I998a, 200I), however, this thesis is false, since microphysical duplicates can differ with respect to the intrinsic property of consciousness. In my view, Merricks' argument is plausible, and extant attempts to reject it are problematic. However, the argument also threatens to make consciousness appear mysterious, by implying that consciousness facts fail to be microphysically determined and that there can be brute and inexplicable differences in consciousness between material things. The paper therefore develops an account that can respect the soundness of Merricks' argument while avoiding these problematic consequences. At the heart of the proposal is the idea that consciousness can be microphysically grounded despite failing to microphysically supervene. The proposed view also has the interesting consequence that consciousness is an intrinsic property despite depending on extrinsic factors for its instantiation.
\end{abstract}

\section{Introduction}

The Doctrine of Microphysical Supervenience states that the intrinsic properties of composite objects supervene on the intrinsic properties of, and interrelations between, their atomic proper parts. We can state a version of this thesis as follows:

(MS) Necessarily, if a composite object, $\mathrm{O}$, is composed of some atoms the XXs, and if $\mathrm{O}$ has intrinsic property $\mathrm{F}$, then if there is an object, $\mathrm{O}^{*}$, composed of some atoms the YYs, and if the YYs have the same individual intrinsic properties and atom-to-atom relations as the XXs, then $\mathrm{O}^{*}$ also has $\mathrm{F}^{2}$

Essentially, (MS) tells us that complex material objects with the same microphysical structure share their intrinsic properties. Without a difference in microphysical structure between two objects, there can be no difference in their intrinsic features.

I Versions of this paper were presented to the Serious Metaphysics Group at Cambridge University and the 2016 Metaphysical Mayhem conference at Rutgers; thanks to all of the participants on those occasions. Thanks especially to Ralf Bader, Selim Berker, Dominic Alford-Duguid, Tim Crane, Ross Cameron, Clint Dowland, Nick Jones, Rae Langton, Mark Johnston, Hugh Mellor, Daniel Muñoz, Jonathan Schaffer, Nathaniel Baron-Schmitt, Ted Sider, Aimee Thomasson, Dean Zimmerman, and two referees at Philosophical Studies. Research for this paper was supported by an Aristotelian Bursary from the Aristotelian Society, a Jacobsen Fellowship from the Royal Institute of Philosophy, a Mind Studentship from the Mind Association, and a Leverhulme Early Career Fellowship from the Leverhulme Trust. My thanks to these funding bodies for their support.

${ }^{2}$ Note that we must restrict the intrinsic properties and atom-to-atom relations that we take into consideration if we are to avoid irrelevant and distracting counter-examples (cf. Merricks I998a: 69-6o; Sider 2003: I40-I4I). Following Merricks (I998a), one option is to restrict our attention to just those intrinsic properties and interrelations that are pure and qualitative, and to all and only those atom-to-atom relations that are spatio-temporal and causal. One might also appeal to Lewisian perfectly natural properties and relations as in Gilmore (2010: I 85 ). 
(MS) is intuitively plausible. According to Merricks (I998a, 200I), however, it can be demonstrated that (MS) is false. In particular, Merricks claims that the property of consciousness provides a counter-example to (MS). ${ }^{3}$ This property, Merricks claims, is an intrinsic property. Yet, it is also possible for two composite objects to differ with respect to this property without differing in their microphysical structure. Therefore, (MS) fails in its full generality. There is at least one intrinsic property, namely consciousness, that does not microphysically supervene.

I believe that Merricks' argument against (MS) is compelling. However, the conclusion of the argument threatens to make consciousness mysterious, by implying that consciousness fails to be microphysically determined and that differences in consciousness between material objects can be brute and inexplicable (cf. section 2). Accordingly, responses in the literature have focused on trying to undercut the argument, albeit in various costly ways (cf. Burke 2003; Dorr 2003; Hawley I 998; Noonan 1999; Sider 2003). By contrast, this paper develops a view that respects the soundness of the argument while avoiding the problematic consequences involving consciousness that it seems to generate. My argument depends on the idea that, consistently with rejecting (MS), we can accept a related thesis, namely, that the intrinsic properties of composite objects, including consciousness, are metaphysically grounded in the properties and relations of their atomic proper parts. The central aim of this paper, therefore, will be to explain how we can accept that the intrinsic properties of complex objects, including consciousness, can be microphysically grounded while also granting that Merricks' case against (MS) succeeds.

Roadmap. The next section sets out the argument against (MS). It then explains why the argument, if sound, threatens to make consciousness mysterious, before briefly criticising some extant attempts to show that the argument fails (section 2). The following sections then develop a view which grants the soundness of the argument without entailing either that consciousness fails to be microphysically determined or that there can be brute differences in consciousness between material things (sections $3 \& 4$ ). The final section of the paper concludes (section 5 ).

\section{$2 \quad$ Against (MS)}

Let us stipulate that two composite objects are microphysical duplicates just in case their constituent atoms have all the same individual intrinsic properties and atomto-atom relations. ${ }^{4}$ Merricks' argument against (MS) can then be stated as follows:

I. It is possible for microphysical duplicates to differ in consciousness.

2. Being conscious is an intrinsic property.

$\therefore$ It is possible for microphysical duplicates to differ in intrinsic properties.

3. If (MS) is true, it is not possible for microphysical duplicates to differ in intrinsic properties.

$\therefore \quad$ (MS) is false.

\footnotetext{
${ }^{3}$ Note that no particular theory of consciousness is required for the argument to work. ${ }^{4}$ Microphysical duplicates in this sense will share all and only those of their microphysical properties that are intrinsic, i.e. those that are a function of what their constituent atom are intrinsically like. Notably, however, we will later on have cause to distinguish between objects that are microphysical duplicates in this restricted sense, and objects that are microphysical duplicates simpliciter, i.e. that share all of their microphysical properties both intrinsic and extrinsic (cf. section 4 ).
} 
The argument is valid. Premise 3., moreover, follows straightforwardly from (MS). The main premises in the argument, therefore, are premises I and 2.

To argue for premise I., Merricks reasons as follows. Consider two human persons, Mary and Martha. We can suppose that these beings are microphysical duplicates in the intended sense. 5 We can then suppose that Mary loses her left foot. As a result, Mary will cease to be a microphysical duplicate of Martha, and will come to be a microphysical duplicate of some undetached proper part of Martha, namely, that part comprising all of Martha besides her left foot. Call that undetached part 'Martha-Minus'. ${ }^{6}$ The case for premise $\mathrm{I}$. is now quite simple. We can suppose that Mary is conscious. But we also know that Martha-Minus is not conscious, because we know that in general, the proper parts of persons are not conscious. Indeed, if Martha-Minus were conscious, then by parity of reasoning, we could show that Martha contains a multitude of conscious beings within her borders. After all, Martha contains various large proper parts that are just like MarthaMinus, and we could run a version of the argument for each one of them. Generalising, we could then show that each one of us contains vastly many conscious beings within our boundaries. This conclusion, however, is absurd. We do not each contain manifold conscious beings within our boundaries. As Merricks (1998a: 63) writes, 'there is not a mighty host of conscious, reflective, pain- and pleasure-feeling objects now sitting in my chair, now wearing my shirt, now thinking about this paper'. We must deny, therefore, that Martha-Minus is conscious. But then, given that Mary and Martha-Minus are microphysical duplicates, this means we have to grant that two material objects could be microphysical duplicates while differing in terms of consciousness. But that, of course, is just to say that premise I is true.

What then of premise 2, the claim that consciousness is an intrinsic property? Merricks argues for this premise by noting that consciousness bears the 'mark' of an intrinsic property, insofar as it could be instantiated by a lonely being. He writes:

Consider the fact that most theists believe that God might never have created; they believe there is a possible world that contains only God. This implies that there is a possible world that contains just a single conscious entity. This implication is coherent; at least, it is not rendered incoherent by the nature of being conscious. If it were, presumably, someone would have developed an argument for atheism along these lines. (Contrast this implication with the claim that there is a possible world that contains just a single entity, three feet from a dog.) If you don't have a taste for theology, consider the solipsistic hypothesis that I-a conscious entity-am all that exists. While surely false, this hypothesis is not rendered incoherent simply by the nature of being conscious. So being conscious bears the "mark" of being intrinsic. An object's being conscious does not require that no other objects exist nor is it rooted in the past or the future. Being conscious is an intrinsic property. (I998a: 6I-62)

\footnotetext{
5 I assume, with Merricks, that human persons are composite material objects of some sort. Throughout, I will write as if we human persons are whole-bodied human beings. However, nothing really turs on that being so. It is enough for us to be complex material things of one sort or another. For example, we might even be brains of human beings or other such parts. In short, any view of the sort that Zimmerman (2003) calls 'sensible materialism' would do to get the argument going.

${ }^{6} \mathrm{It}$ is irrelevant to argue that this kind of case is nomologically impossible. The case need only be metaphysically possible, and this seems hard to deny (cf. Merricks i998a: 64-65).
} 
Not every property that is instantiable by a lonely being is intrinsic. For example, the property of being lonely is itself (in)famously non-intrinsic. However, if a property is instantiable by a lonely being, then either that property is intrinsic or else its instantiation depends on certain negative factors, such as the absence of certain further objects, or else on what is going on at other times. Yet, consciousness is intuitively not like this. Rather, the more natural thought is that being conscious is intrinsic. As Ralf Bader explains, when discussing Merricks' argument,

Intuitively...consciousness is an intrinsic matter. To find out whether $\mathrm{x}$ is conscious we have only have to look at x... what happens elsewhere is not of any relevance to the question whether $\mathrm{x}$ instantiates the property of being conscious (manuscript-a: I9)

There is a strong initial case, therefore, for thinking that consciousness is an intrinsic property. But if that is right, then premise 2 is sound. Given, therefore, that we also have reason to think premise $\mathrm{I}$ is sound, there is a case for thinking that Merricks' argument against (MS) goes through. Consciousness fails to microphysically supervene, and, therefore, it follows that (MS) is false.

Suppose that Merricks' argument is sound. What follows? One way to make progress with that question is to consider the motivations for (MS) in the first place. According to Ted Sider (2003), the reason to accept (MS) is that it captures, or flows from, the plausible thought that macrophysical phenomena are in general metaphysically determined, and therefore explained, by microphysical phenomena:

Why accept supervenience on the small? Because of the unrivaled success of the physics of the small. Physics and related disciplines have been so successful at explaining macroscopic phenomena that it would take a very powerful argument indeed to undermine our faith in this principle. (2003: I40)

One might, therefore, reason from the falsity of (MS) to a failure of microphysical determination. If Merricks' argument is sound, consciousness fails to microphysically supervene. Failure of supervenience, however, implies a failure of metaphysical determination. Therefore, Merricks' argument has the radical consequence that consciousness fails to be determined by the microphysical realm (cf. Dorr 2003: 7I2).

Notably, this is a conclusion that Merricks himself seems to embrace (see esp. Merricks 200I: Ch. 4). In his view, consciousness is an emergent property of persons, and the consciousness facts 'float free' of the underlying microphysical facts. Many of us, however, will be unhappy with this conclusion. After all, many of us accept precisely the kind of microphysicalist picture that Sider gestures at above, and so will baulk at the idea that consciousness fails to be microphysically determined. If this is the upshot of Merricks' argument, therefore, one might conclude that the argument must be flawed, and seek some way of pushing back.

There is a further apparent consequence of the argument that might make us want to resist its conclusion, namely, that there can be brute and inexplicable differences in consciousness between material things. Consider again Mary and Martha-Minus. These beings are microphysical duplicates. But one of them, namely Mary, is conscious, while the other, Martha-Minus, is not. But what could explain this? According to Merricks ( $1998 \mathrm{~b}: 85$ ), the difference is simply 'mysterious'. One 
might worry, therefore, that Merricks' argument against (MS), if sound, not only forces us to accept that consciousness is an emergent property that fails to be microphysically determined, but also that material objects can differ in consciousness without there being any explanation as to why this difference obtains.

In short, while Merricks' argument against (MS) may seem initially compelling, it also threatens to make consciousness mysterious. One might, therefore, think that the right reaction is to find a way of showing that the argument is flawed.

It is far from clear, however, if there is a plausible way to reject the argument. Granting that persons are material objects, and that we do not each contain manifold conscious proper parts within our borders, there are two main options for pushing back: one can deny that person-parts such as Martha-Minus really exist, or one can deny that consciousness is intrinsic. ${ }^{7}$ Yet, both these options have costs.

The first option is to embrace a restricted view of composition according to which human persons do not have large proper parts like Martha-Minus in the first place (cf. Olson I 995; van Inwagen I98 I). For, if there are no such person-parts, then the argument for premise I is undermined, since it can no longer be shown that a person and a proper part thereof might differ in consciousness despite being microphysical duplicates. This move, however, requires us to deny the existence, not only of certain unfamiliar parts of persons such as Martha-Minus, but also of familiar parts such as heads and hands. For, first, we could run a version of the argument against (MS) by focusing on these more familiar parts (cf. Burke 2003). But also, second, it would be intolerably arbitrary to deny that 'foot-complements' like Martha-Minus exist while insisting that there are such things as heads and hands (Olson 1995). Accordingly, the eliminativist option forces us to make the unfortunate claim that certain familiar objects from our everyday ontology do not exist, namely, familiar person-parts like heads and hands and upper-halves.

The second option is to maintain that consciousness is extrinsic rather than intrinsic (Burke 2003; Hawley 1998; Noonan 1999; Sider 2003). The main problem here, however, is that this move conflicts with our intuitive conception of consciousness as an intrinsic property. As we said above, it is natural to think that consciousness is intrinsic, and it would be surprising if this turned out not to be so. As John Hawthorne explains, in a related context:

Granted, there are on occasion surprising discoveries of extrinsically...Yet it seems especially difficult to imagine becoming convinced that consciousness is extrinsic. (2006: n. I0)

In short, we intuitively think of consciousness as being intrinsic, not extrinsic. Whether a being is conscious, whether it has a subjective mental life, depends only on what that thing is like in and of itself. Rejecting this conception of consciousness

\footnotetext{
7 One could deny that persons are material objects without embracing dualism, e.g. by claiming that persons are events constituted by material goings-on. Robinson (2006) argues that such a move could help undermine Merricks' argument; however, see Kovacs (2010) for powerful criticism of this idea. As for the view that each of us contains manifold conscious proper parts, I grant that some philosophers might not be unhappy with such a view. In my view, however, this position is very hard to take seriously (for persuasive argument against this kind of view see Olson 1995). It also generates various important ethical puzzles and paradoxes (cf. Johnston 20I6; Unger 2004, 2006).
} 
is not incoherent. But the move is costly, and this should be acknowledged. ${ }^{8}$ (Cf. Bader manuscript; Merricks I 998b, 200I: Ch. 4 for further criticism of this view.)

These points, of course, are not decisive. However, enough has been said to motivate the project I wish to pursue. ${ }^{9}$ For what I want to do, in this paper, is develop an account that respects the soundness of Merricks' argument against (MS), while avoiding the problematic consequences concerning consciousness that it has plausibly been taken to imply. On the one hand, the account I want to develop will allow us to respect the intuitive status of consciousness as intrinsic, without forcing us to deny that human persons have large proper parts. On the other hand, however, it will enable us to avoid thinking of consciousness as mysterious. Accordingly, the view developed here will allow us to respect what is right about Merricks' case against (MS), without having to accept the troublesome consequences relating to consciousness that many commentators have taken Merricks' argument against (MS) to imply. At the same time, it will avoid the pitfalls associated with the extant responses to Merricks' argument that we canvassed above.

At the heart of the proposed account is the idea that consciousness can be microphysically grounded even if it fails to microphysically supervene. In the next section, therefore, I will begin by introducing that idea. I then develop an account that allows us to make good sense of this position. On the resulting view, consciousness is fully grounded in the microphysical, despite failing to microphysically supervene. Moreover, differences in consciousness between persons and microphysically identical person-parts turn out to be fully explicable rather than being brute.

\section{Grounding without supervenience}

Consider the following principle, formulated not in terms of supervenience, but rather in terms of the distinct notion of metaphysical grounding and in virtue of:

(MG) If a composite object, $\mathrm{O}$, has some intrinsic property, $\mathrm{F}$, then $\mathrm{O}$ has $\mathrm{F}$ in virtue of having some microphysical property $G$ (where having $G$ is a matter of being composed of some atoms exemplifying certain intrinsic properties and/or standing in certain atom-to-atom relations).

\footnotetext{
${ }^{8}$ What about extrinsic mental properties (involving, for example, 'wide' intentional content)? My own view is that if there are such properties, then this shows that consciousness is a 'hybrid' property that can be had both intrinsically and extrinsically (cf. Bader 2013 for discussion of such 'hybrid' properties). So long as consciousness can be had intrinsically, however, the central arguments of this paper will remain substantially the same (though we would need to make appropriate changes to (MS) and to the thesis I will later refer to as (MG), so that the focus is on properties that are had intrinsically rather than properties that are intrinsic). For ease of presentation, I will continue to focus on the idea that consciousness is intrinsic. But those who think there are extrinsic mental properties should keep in mind that we could easily retreat to the very plausible, though somewhat weaker, idea that that consciousness can be had intrinsically (which would follow from there being at least some mental properties that are intrinsic). Cf. Merricks (I998a: 6I, fn. 6).

There are two further points to make. (I) Some mental properties may be 'wide' without thereby being extrinsic. And perhaps these are the only such properties we should grant. And (2) even if some properties are wide and thus extrinsic, they may not be conscious in the sense needed to generate the kind of worries about overpopulation that Merricks is concerned with.

9 For further helpful discussion of the options for responding to Merricks' argument see Kovacs (20IO).
} 
Essentially, this principle is the ground-theoretic analogue of Microphysical Supervenience (MS). ${ }^{\text {IO }}$ We can refer to it, therefore, as Microphysical Grounding (MG). ${ }^{\text {II }}$

Now, (MS) and (MG) are distinct theses. ${ }^{\mathrm{I2}}$ However, it would be strange to believe in (MS) without believing in (MG). After all, supervenience claims like (MS) are often put forward precisely because one takes a grounding thesis such as (MG) to hold. As Bader (2017: I I 5) writes, 'grounding relations are precisely the kinds of explanatory relations that supervenience relations are meant to model and in terms of which supervenience claims can ultimately be explained and justified'. That said, even if those tempted by (MS) will be similarly tempted by (MG), it does not yet follow that advocates of (MG) must accept (MS). Indeed, I will be arguing in what follows that we can accept (MG) consistently with rejecting (MS) for precisely the reasons Merricks gives. Developing this view will then provide us with a way of granting Merricks' argument against (MS) while avoiding the problematic consequences pertaining to consciousness that it appears to generate.

Let me begin by sketching the bare outlines of the view. We can focus on the case of Mary and Martha-Minus. Mary is a person, and Martha-Minus is a personpart. In particular, Martha is a proper part of the distinct human person Martha. Moreover, Mary and Martha-Minus are microphysical duplicates, in that the atoms composing Mary are just like the atoms composing Martha-Minus in terms of their individual intrinsic properties and their atom-to-atom relations. Since I grant that Merricks' argument against (MS) is sound, I accept the following four claims:

[I] Mary is conscious.

[2] Martha-Minus is not conscious.

[3] Consciousness is an intrinsic property.

[4] Mary and Martha-Minus are microphysical duplicates.

${ }^{\text {Io }}$ One might think that a more precise analogue principle would involve an 'inter-object' rather than an 'intra-object' grounding claim, i.e. something along the following lines:

$\left(\mathrm{MG}^{*}\right)$ If an object, $\mathrm{O}$, is composed of some atoms, the $\mathrm{XXs}$, and if $\mathrm{O}$ has some intrinsic property, $F$, then $\mathrm{O}$ has $\mathrm{F}$ in virtue of the fact that the XXs are $\mathrm{G}^{*}$, where for the XXs to be $\mathrm{G}^{*}$ is for them to instantiate certain intrinsic properties and/or stand in certain interrelations.

Interesting questions arise about the precise relationship between $(\mathrm{MG})$ and $\left(\mathrm{MG}^{*}\right)$, though here is not the place to pursue them. I choose to focus on $(\mathrm{MG})$ in the present paper primarily for ease of presentation, and I doubt that much of great importance turns upon this choice. For discussion of a principle very much like ( $\left.\mathrm{MG}^{*}\right)$ and of a puzzle it gives rise to, see Moran (manuscript).

${ }^{\text {II }}$ For an introduction to the relevant notion of metaphysical grounding see Audi (201 2); Fine (2012); Rosen (2010); and Schaffer (2009), among many others. There are many controversies about the precise nature of metaphysical grounding, but we do not need to engage with these here. What I have in mind is a relation of metaphysical determination that is hyperintensional in character and that has certain distinctive formal characteristics, namely it is asymmetric, irreflexive and transitive. I assume that grounding claims in general be expressed by the in virtue of locution.

${ }^{12}$ This flows from the fact that grounding and supervenience are distinct relations with different characters. Cf. Schaffer (20 17: Io): 'With supervenience, one simply has two families of properties, and one can only ask whether or not they modally co-vary. With grounding, one has a relation of directed dependency, with a more articulated structure'. Cf. Horgan (I993); Kim (I993: I67). 
What Merricks' argument effectively brings out is that these four claims jointly imply that (MS) is false. What I want to say, however, is that despite this, we can nonetheless hold all of these claims consistently with accepting (MG). To help bring out the details of the view, it will be useful to consider a fairly immediate problem that arises if we try to accept (MG) consistently with claims [I] - [4].

If (MG) is true, then [I] and [3] jointly imply the following, namely, that there is some microphysical property, $\mathrm{M}$, such that Mary is conscious in virtue of having $\mathrm{M}$-whereby having $\mathrm{M}$ is a matter of being composed of some atoms with certain intrinsic properties and/or certain interrelations. We thus obtain:

\section{[5] Mary is conscious in virtue of instantiating $\mathrm{M}$.}

By [4], however, we know that Martha-Minus also instantiates this microphysical property. And yet by [2], we know that Martha-Minus is not conscious. The view I wish to hold, therefore, implies that while Mary and Martha-Minus both instantiate the same consciousness-making microphysical property M, only Mary is conscious for this reason. In other words, as well as [5], we must also accept:

[6] Martha-Minus also instantiates M, but is not conscious for that reason.

If it is coherent to hold both [5] and [6], then we can hold a view on which consciousness facts are microphysically grounded despite failing to microphysically supervene. Whenever a person is conscious, she will be conscious in virtue of certain underlying microphysical properties. Moreover, this will be the case despite the fact that certain microphysically identical person-parts, who share those same consciousness-making microphysical properties, are not themselves conscious. A person and a person-part might therefore share the same consciousness-making microphysical properties, and yet only the person will be conscious in virtue of having them. Clearly, this promises a way of accepting Merricks' argument against (MS) without having to deny that consciousness is microphysically determined, and hence without having to view consciousness as a mysterious emergent property.

One might well wonder, however, whether it really is coherent to jointly hold both [5] and [6]. In particular, the trouble is that these two claims jointly imply the falsity of an initially attractive principle governing the grounding relation, to the effect that grounding relations are fully general in character (so that if $a$ is $\mathrm{F}$ in virtue of being $\mathrm{G}$, then any possible $b$ that is $\mathrm{G}$ must be $\mathrm{F}$ for that reason). In the next sub-section, I will set out this worry, and then develop a response. This will help draw out further important details of the view that I wish to defend.

\section{I Rejecting Generality}

Consider the following principle, which we can refer to as:

$$
\text { Generality: } \forall(\mathrm{F}) \forall(\mathrm{G}) \exists(\mathrm{x})(\mathrm{Gx}<\mathrm{g} \mathrm{Fx}) \rightarrow \square \forall(\mathrm{y})((\mathrm{Gy} \rightarrow(\mathrm{Gy}<\mathrm{g} \text { Fy }))
$$

Reading ' $<\mathrm{g}$ ' as 'grounds', the principle tells us that if something is $\mathrm{F}$ in virtue of being $G$, then, necessarily, anything that is $G$ is $F$ in virtue of being $G$. That is, 
whenever the fact that $x$ is $G$ makes it the case that $x$ is $F$, it follows that if any possible object $y$ is $G$, the fact that $y$ is $G$ will make it the case that $y$ is $F^{13}$

The principle is intuitively plausible. As Gideon Rosen explains:

If Fred is handsome in virtue of his symmetrical features and deep green eyes, then anyone with a similar face would have to be handsome for the same reason. Particular grounding facts must always be subsumable under general laws, or so it seems. (20 I o: I32)

The main idea is that grounding claims are fully general in character. When something is $F$ in virtue of being $G$, this means that across the board, things that are $G$ are $\mathrm{F}$ for that reason. As Audi (2012: 104) puts it, the intuition is that grounding relations 'do not vary from instance to instance of the properties involved in the facts in question', and that, likewise, 'they do not vary from world to world'. ${ }^{14}$

If Generality is true, it is not possible to hold both [5] and [6], contrary to what I want to say. For suppose that $[5]$ is true. By Generality, it then follows that any object whatsoever that has microphysical property $\mathrm{M}$ must be conscious for that reason. Yet, given [5], this is incompatible with [6], the claim that MarthaMinus also instantiates $\mathrm{M}$, and yet fails to be conscious in virtue of having it. ${ }^{\text {Is }}$

In order to have a coherent view, therefore, we need a way of rejecting GENERALITY. In particular, we need a way of claiming that while Mary is conscious in virtue of having $M$, and while Martha-Minus also has $M$, Martha-Minus is not conscious for that reason. My goal will be to develop precisely such an account.

To begin, consider the following further passage from Rosen (2015), this time expressing scepticism about Generality. According to Rosen, this principle:

...is not self-evident. It amounts to the claim that when $\Phi a$ grounds $F a$ in some particular case, the capacity of the first fact to ground the second derives entirely from the distinctive powers of the predicable $\Phi$, and not from the combination of $\Phi$ and $a$ together. But why shouldn't there be cases in which $\Phi$ and $a$ conspire to make the case that $F a$, in part thanks to $\Phi$ and its distinctive powers, but also in part thanks to $a$ and its distinctive powers? (2015: 199)

There is a lot that we might take from this passage. For present purposes, however, I wish to focus just on the following point. As I see it, Rosen is making room for

${ }^{13}$ Cf. the principle that Rosen (2015) dubs 'Weak Formality'. (For the stronger 'Formality' principle, see Rosen 2010). We find a very similar generality principle discussed in Audi (2012: I03-I04). For general critique of the principle, and relevant discussion, see Moran (2018).

${ }^{14}$ Note that the truth of GENERALITy would also help to explain why a related principle is true, which, following deRossett (20I0), we can refer to as the Determination Constraint. This tells us that if something is $F$ in virtue of being $G$, then, necessarily, anything that's $F$ is $G$. As Wilsch (20 I 5) explains, this principle is very plausible, but also needs explaining. The present point is that if Generality is true, this would explain the principle in a straightforward way. For, given that ground is factive, Generality straightforwardly implies the Determination Constraint.

is Notice that to generate the worry here, standard grounding necessitation principles will not do. Standard such principles say that if a is $F$ in virtue of being $G$ then necessarily if $a$ is $G$ then $a$ is $F$ (i.e. they concern only one object: if $a$ itself is $F$ in virtue of being $G$, then necessarily, whenever $a$ is G, $a$ is F.) But [5] and [6] are inconsistent only if we have a principle to the effect that grounding properties necessitate the properties they ground, regardless of the particular objects involved. 
the possibility of there being two objects, $a$ and $b$, such that although $a$ and $b$ are both G, only $a$ is $F$ for that reason. The idea, moreover, is that the reason only $a$ gets to be $\mathrm{F}$ in virtue of being $\mathrm{G}$ is due to some difference in nature between $a$ and $b$ themselves. That is, the idea is that there is some difference that obtains between $a$ and $b$, such that because of this difference, while both objects instantiate the same grounding property $\mathrm{G}$, only $a$ instantiates the grounded property $\mathrm{F}$ for that reason.

One plausible way-though not the only such way-to develop this thought is to appeal to the idea that differences in kind can make for differences in what grounding relations a thing can enter into. It is natural to think that certain properties can be instantiated only by certain kinds of thing. ${ }^{16}$ If that is right, however, then we can go on to imagine cases of the following sort. We have two objects, $a$ and $b$, and these are different kinds of thing. In particular, $a$ is the kind of thing that can be F, while $b$ is not. We then suppose it happens that both $a$ and $b$ instantiate the same base property, G. Since $a$ is the kind of thing that can be F, we can allow that $a$ is $F$ in virtue of being $G$, i.e. that in the case of $a$, being $G$ makes for being $\mathrm{F}$. But we can also claim that $b$ will not be $\mathrm{F}$ in virtue of being $\mathrm{G}$, despite being $\mathrm{G}$ - the explanation being that since $b$ isn't the kind of object that can be $\mathrm{F}$ in the first place, it is not the kind of object that can be F in virtue of being G. So here we have a case in which, just as Rosen supposes in the above passage, two objects share the same grounding property $G$, and yet only one of them gets to be $F$ for that reason, whereby this is due to a prior difference in nature between them, and in particular, due to the fact that they are different kinds of thing.

On this view, the kind of thing an object is can determine the range of properties that it can have, and, hence, the range of grounding relations that it can enter into. One might ask, however, what role exactly kinds are playing here. To have a counter-example to Generality, we need a case in which (i) $a$ is F fully and solely in virtue of being $\mathrm{G}$, while (ii) $b$ is $\mathrm{G}$ but fails to be $\mathrm{F}$ for that reason. So, we cannot incorporate the role of kinds by treating them as partial grounds. That is, the view cannot be that when $a$ is F, $a$ is F partly in virtue of being G and partly in virtue of being the kind of thing it is. How, then, are we to model the role that kind-facts are playing in the story? If kinds are not partial grounds, what are they?

There are, it seems to me, various avenues we might pursue here. My preferred option, however, is to appeal to the machinery of 'conditional grounding'. In the causation literature, a distinction is sometimes drawn between causes and conditions. The idea is that in some cases, an event $c$ will only cause some further event $e$ given that certain background conditions $\{\mathrm{X}\}$ are met. The background conditions, moreover, are not construed as being partial causes of $e$. Rather, they are construed as that which enables the cause $c$ to perform its causal work in generating $e$. Now I believe that we can also draw a similar distinction in the case of ground. That is, we can maintain that in some cases, one fact $\Gamma$ grounds a further fact $\Delta$ only given that certain background conditions $\{C\}$ are met. These conditions,

${ }^{16}$ This is especially plausible on the kind of neo-Aristotelian metaphysical picture that draws a sharp distinction between what an object is on the one hand, and merely how it is on the other. On this view, to say what an object is, one has to specify the kind of thing it is. Whereas to specify how it is, one has to list its properties/relations. A crucial part of the picture is that in a certain sense, the kind of thing an object is classifies as prior to what properties it has: being the kind of thing it is determines the range of features it can have, and so in this sense, what the object is determines how it can be. For a recent defence of this kind of picture see Wiggins (200I); cf. also Moran (2018). 
moreover, are not to be taken as further partial grounds. Rather, $\Gamma$ is to be conceived as fully grounding $\Delta$, and the role of the conditions is that of enabling $\Gamma$ to act as a ground of $\Delta$ in the first place, i.e. to enable $\Gamma$ to perform its grounding work in making it the case that $\Delta$. On this kind of view, then, as Kit Fine (2015: 3 II) puts it, '[c]ertain conditions may provide a background to other conditions having a determinative role even though they do not themselves play a determinative role'. In other words, as Bader (manuscript-b: 4) writes, '[n] ot everything that plays a role in making it the case that something else is the case needs to play a grounding-role', since ' $[\mathrm{t}]$ hings can also be relevant by being conditions that must be satisfied in order for other things to do their grounding work' ${ }^{17}$

The idea that we can distinguish between grounds and conditions in this way has been appealed to in several different contexts in the recent metaphysics literature. ${ }^{18}$ What I want to do here, however, is show that if we help ourselves to this machinery, then we can make good sense of the idea that kind-differences between objects can make for differences in terms of the grounding relations they can enter into. On such a view, there can be cases where an object, $a$, is $\mathrm{F}$ in virtue of being $G$, but only given that it meets the background condition of being a certain kind of thing. Being that kind of thing is therefore not a ground of being $\mathrm{F}$ for that object. Rather, being that kind of thing is what enables the object to be $\mathrm{F}$ in virtue of being $\mathrm{G}$. And so if some other object, $b$, could instantiate $\mathrm{G}$ without being the kind of thing that can be F, then we would have a counter-example to Generality. One object, $a$, would be $F$ in virtue of being $G$, conditional on being a certain kind of thing. The other object, $b$, would then be $\mathrm{G}$ without being F. Due to being the wrong kind of thing, $b$ 's possession of $\mathrm{G}$ would fail to make it so that $b$ is $\mathrm{F}$.

At this point, then, we are in a position to explain how [5] and [6] might both be true, i.e. how it could be the case that while Mary is conscious in virtue of having M, Martha-Minus also has M but fails to be conscious for that reason. All we need is the further idea that Mary and Martha-Minus differ in kind, whereby this difference makes it so that Mary is able to be conscious while Martha-Minus is not so able. In other words, we need to claim that while human persons like Mary are the kind of thing that can be conscious, mere person-parts like Martha-Minus are not. For what we can then say is this. When Mary is conscious, she is conscious in virtue of having microphysical property $\mathrm{M}$. However, she is conscious in virtue of having

${ }_{17}$ Note, then, that the distinction between grounds and conditions is meant to be metaphysically robust. In the causation literature, it is common to deflate the analogous causes/conditions distinction, arguing that what counts as a cause and what as a background conditions can depend on contextual matters. The view I have in mind here, however, which distinguishes grounds and conditions, implies a robust distinction between the things that are grounds and the things that are enabling conditions, which is not context-sensitive in this way. (For a defence of the idea that we can draw a metaphysically robust distinction between grounds/conditions see Bader 2015.)

${ }^{18}$ For example, Fine $(2015,2016)$ argues that we need to make use of conditional grounding in order to properly model the role that the existence of facts play with respect to the holding of diachronic identities. Meanwhile, Ralf Bader (manuscript-b) and Ted Sider (2020) argue (independently) that we should appeal to conditional grounding (which Sider refers to as 'groundingqua') in order to handle the problem of truth-grounding universal generalisations. Moran (20 I 8) has put the view to work in the context of dealing with the problem of coinciding objects. And Bader (2015) has argued that we need the notion of conditional grounding in order to properly model the way in which reasons can vary across contexts (cf. Dancy 2004; Ch. 3). The notion of conditional grounding is also similar to the notion of an 'anchor' in Epstein (2015), due to the fact that anchors are not grounds but rather that which enables other things to do their grounding work. 
$\mathrm{M}$ only given that she meets a certain background condition, namely, that of being a certain kind of thing. Martha-Minus, however, is not the kind of thing that can be conscious. So, while Martha-Minus also has M, she fails to be conscious for that reason. That is, both Mary and Martha-Minus have the same (conditionally) consciousness-making microphysical property M. But only Mary is conscious in virtue of having this property. And this is due to a prior difference in kind between them.

Is it plausible to think that a difference in kind between Mary and MarthaMinus could help to explain why only one of them gets to be conscious in virtue of having the shared microphysical property M? There are, I think, grounds for answering affirmatively. One plausible thought, for example, is that in general, being a person is a background condition on being conscious. ${ }^{19,20}$ Plausibly, however, only Mary meets this condition. Perhaps Martha-Minus belongs to the kind Aggregate, or Mere Sum. But plausibly, Martha-Minus, unlike Mary, is not a person. Accordingly, there is a case for thinking that we can locate a difference in kind between Mary and Martha-Minus, and more generally between persons and the large proper parts thereof, that will allow us to maintain, in the manner sketched above, that even when a person and a person-part share the same consciousnessmaking microphysical properties, only the person will be conscious for that reason.

Note that this is just one way of developing the kind of view that I am interested in defending. There are also further options. For instance, one might think that Mary is most fundamentally an animal, but that Martha-Minus is not. One might then claim that (at least when it comes to material objects) being an animal is a background condition on being conscious, and hence on being conscious in virtue of having the relevant base properties. ${ }^{21}$ Another option is to focus on the kind of thing that person-parts like Martha-Minus are. Again, perhaps such parts are aggregates of matter. Moreover, it is plausible to think that mere aggregates of matter are not the kind of thing that can be conscious. So, we might consider view on which Mary would be conscious in virtue of having $M$, because whatever kind of thing she is, we know that since she is a person, she is the kind of thing that can be conscious, while Martha-Minus, as a mere aggregate of matter, would fail to be conscious in virtue of having $\mathrm{M}$, due to being the wrong kind of thing. ${ }^{22}$

There is a general way, therefore, to maintain [5] and [6] at once, and to reject the Generality thesis in a principled manner. In particular, we can appeal to a difference in kind between Mary and Martha-Minus in order to make sense of the idea that while Mary is conscious in virtue of having M, Martha-Minus is not. ${ }^{23}$ In

I9 Shoemaker (2008) develops this view by claiming that persons persist by means of psychological continuity, and that persisting in this way is necessary for being conscious.

${ }^{20}$ Importantly, for the view that personhood is a condition on consciousness to be at all plausible, we need a weightier conception of personhood than the standard neo-Lockean conception, on which being a person is just a matter of being a self-conscious entity. Rather, we need to view persons as a distinctive kind of thing, whereby being this kind of thing is a precondition for consciousness. Cf. Bader (manuscript-a: fn. 6).

${ }^{21}$ For this suggestion see Ayers (I969: 98-99): '[I]t is at least a philosophical possibility, and by no means contrary to common sense or to science, that any experience is necessarily the experience of an animal...'

${ }^{22}$ In this second case, rather than Mary meeting a condition that enables her to be conscious in virtue of having M, Martha-Minus meets a condition that disables her from being conscious for that reason. But the crucial difference between Mary and Martha-Minus is still a difference in kind.

${ }^{23}$ Instead of appealing to a difference in kind, we might instead appeal to other resources. For instance, we might appeal to a difference in essence between persons or person-parts, or to a 
turn, this allows us to embrace a view that is consistent with (MG) but not (MS). On that view, microphysical duplicates can differ in consciousness, and so (MS) is false. But consciousness is nonetheless microphysically determined. For when a person is conscious, she is conscious in virtue of her microphysical properties. It is just that the grounding relation only holds given that the person is the kind of thing she is. Because the person is the kind of thing she is, she meets a background condition that enables her to be conscious in virtue of having certain microphysical properties. The person-part, however, is a different kind of thing, and fails to meet the requisite background condition. And so, despite having the same microphysical properties, the person-part is not conscious in virtue of instantiating them.

Note that this view also enables us to avoid saying that differences in consciousness between persons and person-parts that are microphysical duplicates are brute. For, on the account we have developed, an explanation can be given as to why these differences obtain. Persons and person-parts differ in kind. Persons are the kind of thing that can be conscious, person-parts are not. So even when a person-part has all the necessary microphysical properties for being conscious, it won't be conscious for that reason. Only the person will be conscious in virtue of having those properties, since only the person meets the condition of being the right kind of thing.

On the proposed view, therefore, we can agree with Merricks that (MS) is false. But we can also avoid viewing consciousness as mysterious. When a person is conscious, this fact will be grounded in more basic microphysical facts. And when a person and a person-part that happen to be microphysical duplicates differ in consciousness, we can explain why this is so in terms of a prior difference in kind.

\subsection{A Simpler Account?}

One might wonder, at this juncture, whether the distinction between kinds and conditions is really necessary. Consider the following simpler account. To be conscious, one has to be the right sort of thing. Therefore, when Mary is conscious, she is conscious partly in virtue of her microphysical profile, and partly in virtue of being the kind of thing she is. So even though Martha-Minus may have the right microphysical profile, it does not follow that she is conscious. In general, if $\mathrm{x}$ is $\mathrm{F}$ in virtue of being $\mathrm{G}$ and $\mathrm{H}$, and $\mathrm{y}$ is also $\mathrm{G}$, it does not follow that $\mathrm{y}$ must be F. So

difference in form. Insofar as it is plausible to view the kind, or essence, or form...etc. of an object as able to determine the range of properties a thing can have, we could appeal to any such a difference in order to offer a structurally similar account to the one that I have sketched in the main text. So even those unsympathetic to the neo-Aristotelian metaphysic sketched above could still endorse a version of the general view I wish to hold, on which we can accept (MG) while rejecting (MS).

We might also impose maximality itself as the condition that persons must meet in order to be conscious. That is, rather than requiring that persons be this or that kind of thing, we might say that to be conscious $\mathrm{x}$ must be a maximal whole. My own view, however, which I lack space to develop here, is that kinds, if treated sufficiently robustly (as in fn. I6) are much better candidates to act as conditions on being conscious. Part of the reason is that I think we can explain plausibly why kinds are maximal (cf. section 4) and then, in a second step, appeal to (certain) kinds as plausible conditions on consciousness. To pursue the other strategy, however, one would have to directly argue that maximality is a condition on consciousness, which seems to me harder to do. 
we can have a much simpler account on which, rather than acting as conditions, kinds act instead as partial grounds of consciousness. Why not prefer this view? ${ }^{24}$

To answer this question, we need to look at a further objection to the proposed picture. The basic worry is that the proposed view has only shifted the bulge in the carpet. Originally, we wanted to explain how a person like Mary and a large personpart like Martha-Minus might differ in consciousness, despite being microphysical duplicates. In answer to this explanatory challenge, we have appealed to a difference in kind. Now, however, the difference in kind needs explaining. How, after all, could Mary and Martha-Minus be different kinds of thing, given that they are microphysical duplicates? Is the kind-difference not just as mysterious and problematic as the original difference in consciousness that we wanted to explain?

As we will see, to meet this challenge, we will need to argue that extrinsic differences can underwrite the relevant differences in kind. In light of this, however, we will then face a challenge as to how consciousness could be intrinsic. Ultimately, I want to argue that this challenge can be met, but only if we treat the relevant kind-theoretic facts as conditions rather than as grounds. Accordingly, there is in fact principled reason to reject the simpler view sketched just above, and to prefer the view that draws a distinction between grounds and enabling conditions. This will become clearer as we work through these issues in the following section.

\section{Kind-Differences, Maximality, and Intrinsicality}

On the account I have proposed, Mary and Martha-Minus differ in kind, and this helps to explain why they differ in consciousness. For concreteness, let us suppose that the relevant difference in kind is that only Mary is a person, where being a person is taken to be a background condition on being conscious. The view is then that while Mary and Martha-Minus have the same consciousness-making microphysical properties, only Mary is conscious in virtue of having them, because the grounding relation holds conditionally, i.e. only given that Mary meets the condition of being a person. Since Martha-Minus fails to meet this condition, she fails to be conscious in virtue of having those same microphysical properties.

There is an important question as to how Mary and Martha-Minus could differ in kind, given that they are microphysical duplicates. The question, moreover, is especially pressing in light of the fact that a crucial aim of the present project is to preserve a plausible microphysicalist metaphysics, on which the facts about composite objects are grounded in underlying microphysical facts. In general, it is plausible to think that facts about what kind of thing an object is are not basic facts but are rather grounded in certain facts that are more basic. ${ }^{25}$ Within a microphysicalist framework, moreover, it will be plausible to think that kind-differences must be grounded in underlying microphysical differences. Mary and Martha-Minus, however, are microphysical duplicates. So how could these objects differ in kind?

One option here would be to insist that kind-differences can be basic and thus ungrounded. Perhaps, when we specify what kind of thing a given object is, we say

${ }^{24}$ There is, in fact, room for a version of my view on which kinds act as partial grounds. However, this version of the view still requires the machinery of conditional grounding if it is to avoid the kind of worry that we focus on in the next section. Cf. fn. 29.

${ }_{25}$ This is certainly so for macroscopic objects, such as human persons are on a materialist view (of the sort I have been presupposing here). Cf. Fine (2008: 105) on statues and pieces of clay. 
something about its nature, or its essence, and maybe facts about the nature or the essence of an object are not apt for metaphysical grounding (cf. Dasgupta 20I4). ${ }^{26}$ However, while such a view may be well worth taking seriously, it is not at all in the spirit of the kind of microphysicalist picture that we have been looking to preserve. Fortunately, however, there is a better way. As it turns out, the difference in kind between Mary and Martha-Minus can be understood as grounded in underlying microphysical differences, despite the fact that Mary and Martha-Minus are microphysical duplicates. This is because, for all that has been said, there might be extrinsic microphysical differences between Mary and Martha-Minus that are relevant to grounding the difference in personhood between them.

To say that Mary and Martha-Minus are microphysical duplicates (in the sense of that term we've been using) is to say that the atoms composing Mary are just like the atoms composing Martha-Minus in terms of both their individual intrinsic properties and their (restricted) atom-to-tom relations (cf. section 2). Being microphysical duplicates thus guarantees that Mary and Martha-Minus do not differ in terms of any intrinsic microphysical property. In general, the intrinsic microphysical properties of an object are a function of what the atoms composing them are intrinsically like. So, since the atoms composing Mary are intrinsically just like the atoms composing Martha-Minus, there is no room for Mary and Martha-Minus to differ in terms of their intrinsic microphysical properties. ${ }^{27}$

However, it does not follow that there are no microphysical differences between Mary and Martha-Minus. In particular, there is still room for extrinsic microphysical differences between them. After all, Mary and Martha-Minus are not microphysical duplicates in the strongest possible sense, i.e., it is not the case that the atoms composing Mary differ neither intrinsically nor extrinsically from those composing Martha-Minus. Accordingly, Mary and Martha-Minus can be said to have different extrinsic microphysical properties. Moreover, as we will see, this is what will enable us to explain the difference in personhood (in kind) between them.

In general, it is plausible to think that kind-properties such as personhood are maximal properties (cf. Sider 200I, 2003), where, roughly, a property $\mathrm{F}$ is maximal just in case the proper parts of Fs cannot be Fs (due to being proper parts of Fs). As Sider explains:

Ordinary sortal predicates typically express maximal properties, where a property, F, is maximal, roughly, if large parts of an F are not themselves Fs. A large part of a house-all of the house-save a window, say-does not itself count as a house. A large part of a cat-all of it save the tail, say-does not itself count as a cat. Otherwise in the vicinity of every house there would be a multitude of houses; in the vicinity of every cat there would be a multitude of cats...Maximality is a kind of border-sensitivity: whether something counts as a house or cat depends on what is going on around its borders (2003: I 39)

Maximal properties, however, are paradigmatic extrinsic properties. If being $\mathrm{F}$ is maximal, then whether $\mathrm{x}$ is $\mathrm{F}$ depends, at least in part, on x's surroundings, and in

\footnotetext{
${ }^{26}$ Moran (2018) develops this kind of view.

${ }^{27} \mathrm{I}$ am assuming, here as throughout, that micro-based properties of the form being composed of atoms with such and such intrinsic properties and interrelations are themselves intrinsic. After all, such properties are a function of what the atoms composing an object are intrinsically like. For some interesting complications here, however, see Moran (manuscript).
} 
particular, on whether $\mathrm{x}$ is embedded within a larger being that is itself an F. Thus, if personhood is maximal, then personhood is also extrinsic. Whether a thing is a person will depend, at least in part, on whether it is embedded within something that is a person.

How does this help with the explanatory challenge we are concerned with? Suppose that being a person is intrinsic. If, in general, the intrinsic features of objects are grounded in underlying intrinsic microphysical properties, as per (MG), then it would follow that there must be some intrinsic microphysical property $M_{I}$ such that Mary is a person in virtue of having $\mathrm{M}_{\mathrm{I}}$. But then Martha-Minus will also have $\mathrm{M}_{\mathrm{I}}$, since Martha-Minus is an (intrinsic) microphysical duplicate of Mary. But then the worry emerges that Martha-Minus must also be a person in virtue of having $\mathrm{M}_{\mathrm{I}}$. For, why should only Mary be conscious in virtue of having this microphysical property?

Of course, one could try to push back here just as we did before, namely, by utilising the machinery of conditional grounding and arguing that only Mary gets to be a person in virtue of having $\mathrm{M}_{\mathrm{I}}$. However, we would then face the challenge of specifying some relevant difference between Mary and Martha-Minus that would explain why the grounding relation only obtains in Mary's case. But then the problem would just re-emerge once more: unless the relevant difference were brute, the fact that Mary and Martha-Minus are microphysical duplicates would put pressure on the idea that the relevant difference obtains. Accordingly, we must pursue a different strategy if we are to account for the kind-difference between Mary and Martha-Minus.

What we can do, at this juncture, is abandon the idea that being a person is an intrinsic matter. Instead, we can maintain that personhood is extrinsic. Given this assumption, a plausible microphysicalist metaphysics will ensure that Mary is a person in virtue of having some extrinsic microphysical property $M_{E}$ (or set thereof). However, there is no guarantee that Martha-Minus must also have this property. In fact, since personhood is maximal, we have reason to deny that Martha-Minus will instantiate $\mathrm{M}_{\mathrm{E}}$. For having $\mathrm{M}_{\mathrm{E}}$ will then involve, at least in part, being composed of atoms that are not embedded within a larger plurality of atoms composing a person. But clearly, while the atoms composing Mary meet this condition, those composing Martha-Minus do not. Therefore, only Mary has the grounding property $\mathrm{M}_{\mathrm{E}}$, and so the argument for thinking that Martha-Minus must also have this property and must therefore also be a person is undermined.

In short, if we view personhood as maximal, and hence extrinsic, we can maintain that Mary and Martha-Minus differ in personhood without having to deny that kind-differences are grounded in underlying microphysical differences. This view, however, does raise at least one further question. Recall that our original aim was to explain how we can accept Merricks' argument against (MS) without having to accept the untoward consequences regarding consciousness that it is widely taken to imply. And recall that this involves granting that consciousness is an intrinsic property. The question now is whether the account we've ended up with really is consistent with taking consciousness to be intrinsic. After all, on the proposed view, a part of what explains why Mary is conscious is the fact that she is a person. But to explain why Mary is a person, we must appeal to extrinsic factors. Accordingly, extrinsic factors seem to end up being relevant to explaining why Mary is conscious. Yet that appears to threaten the idea that consciousness is an intrinsic property. 
It is at this point that we can appreciate the importance of our earlier appeal to conditional grounding, and the idea that kind-membership-facts act as background conditions on being conscious rather than grounds of consciousness. For it is this that will allow us to maintain that despite depending on extrinsic facts involving kind-membership for its instantiation, consciousness is nonetheless intrinsic.

Consider once again the fact that Mary is conscious. Suppose we said that Mary is conscious partly in virtue of having intrinsic microphysical property $M_{I}$, and partly in virtue of being an object of kind $\mathrm{K}$ (e.g. a person), where being a $\mathrm{K}$ is an extrinsic matter. In that case, we could no longer say that being conscious is intrinsic. After all, intrinsic properties are properties that are always had intrinsically, and that are never had extrinsically (cf. Bader 20I3). ${ }^{28}$ However, if Mary is conscious at least in part in virtue of having some extrinsic kind-property, then Mary instantiates consciousness extrinsically, not intrinsically. Consciousness would thus turn out to be extrinsic, rather than intrinsic.

On the view I am recommending, however, Mary is not conscious, even in part, in virtue of instantiating some extrinsic kind-property. Rather, the view implies that Mary is conscious solely and fully in virtue of instantiating the intrinsic microphysical property, $\mathrm{M}_{\mathrm{I}}$. The role of the kind-property is that of background condition: Mary is conscious in virtue of having $\mathrm{M}$ only on the condition that she is the kind of thing she is. Being that kind of thing, therefore, is not a part of what makes Mary conscious. Rather, being that kind of thing is what enables Mary to be conscious in virtue of instantiating the relevant intrinsic microphysical property. In light of this, I want to say, my account is fully compatible with viewing consciousness as intrinsic. ${ }^{29}$

In making this claim, I am relying on something like the following principle:

INTRINSICALITY: If $x$ is $F$ solely and fully in virtue of being $G$, and if $G$ is intrinsic, then $\mathrm{x}$ has $\mathrm{F}$ intrinsically.

The idea is that for $\mathrm{x}$ to have a property intrinsically, it is sufficient for that property to have intrinsic grounds. The crucial point is that on the account I am proposing, this principle is not violated. Whenever a person is conscious, she is conscious only in virtue of intrinsic microphysical properties. And so, whenever a person is

${ }^{28}$ On the difference between (i) the local 'intrinsically/extrinsically', distinction, which distinguishes two ways a property can be had, and (ii) the global 'intrinsic/extrinsic' distinction, which distinguishes two second-order properties that properties can have, see Dunn (I990: I83) and Humberstone (1996: $206 \&$ 227-228).

29 There is an alternate way of developing the kind of account I wish to defend here that does not have this consequence, on which we are to view kind-properties as both intrinsic and subject to maximality constraints. Suppose we said that when $\mathrm{x}$ is a person, $\mathrm{x}$ is a person solely in virtue of instantiating certain more basic intrinsic properties, but only on the condition that $\mathrm{x}$ is not a larger proper part of a person. On this view, we could maintain that maximal kind-properties like personhood are intrinsic: when a being instantiates one of these kinds, this will be in virtue of some particular set of intrinsic base properties, but the grounding relation will hold only given that the being in question meets certain maximality conditions. Notably, such a view would also enable us to view kind-facts themselves partial grounds of consciousness - when $\mathrm{x}$ is conscious, the grounding relation would hold unconditionally, and the fact that $\mathrm{x}$ is the kind of thing she is would be a partial ground of her being conscious; however, the fact that $\mathrm{x}$ is the kind of thing she is would be conditionally grounded in certain microphysical properties whereby the condition is that the person meet a certain maximality constraint. (Thanks to Nick Jones for suggesting this alternate view.) 
conscious, she has this property intrinsically. To be sure, the person instantiates consciousness only given that she is the right kind of thing, and being that kind of thing is an extrinsic matter. However, extrinsic kind-facts do not enter into the grounds of consciousness, but rather function as background conditions. Accordingly, while there is a robust sense in which consciousness depends on extrinsic factors for its instantiation, this is no threat to the idea that consciousness is intrinsic, since it does not imply that consciousness is ever grounded in anything other than more basic intrinsic properties. ${ }^{30}$

This point is important when it comes to appreciating the difference between the account developed here and the view developed previously by Burke (2003) and Sider (2003). On the latter view, consciousness is taken to be maximal and hence is viewed as an extrinsic property. So, Merricks' case against (MS) is undermined, and we are left with a way to explain why persons like Mary and personparts like Martha-Minus differ in consciousness even despite being microphysical duplicates. This maximality account, however, requires us to abandon the intuitive status of consciousness as intrinsic. My own view, by contrast, appeals to maximality only when grounding the difference in kind between persons and person-parts. Therefore, since kinds are taken as conditions rather than grounds, the appeal to maximality does not conflict with the intuitive idea that consciousness is intrinsic. I take this to constitute an important advantage over extant maximality accounts on which consciousness itself is taken to be maximal and thus extrinsic.

A further thing worth mentioning is that my solution avoids what can be called the 'irrelevant determiner' objection (Bader manuscript-a; Merricks I998b, 200I). Suppose consciousness is extrinsic. Still, it has to be extrinsic in a way that prevents the large undetached parts like Martha-Minus from being conscious. Yet, one might worry that the mere fact that such a being is embedded in a larger conscious being is not the kind of extrinsic difference that can make the difference here. (Martha and Martha-Minus might have differed only by an atom or two, after all). Maximality thus seems to lead to irrelevant determiners: factors that are intuitively irrelevant to consciousness somehow mattering to whether a being is conscious or not. My view, however, avoids this, since maximality as a condition on kinds is well-motivated. Hence, there is no analogue of the irrelevant determiner objection, since maximality does matter to kind-membership in a clear and obvious way. On the resulting view, maximality matters to the instantiation of personhood, and personhood matters to the instantiation of consciousness. Maximality is thus relevant

\footnotetext{
${ }^{30}$ One worry here is that this view conflicts with the plausible thought that intrinsic properties must be preserved across Lewisian duplicates. After all, so the thought goes, Mary and MarthaMinus are surely such duplicates. So if consciousness is intrinsic, and yet Mary and Martha-Minus differ in consciousness, then the intuitive idea that Lewisian duplicates must share intrinsics will be undermined. (Thanks to Ted Sider for raising this objection.) In reply, I want to make two main points. First, it isn't clear just what the cost is, in the present context, of denying that Lewisian duplicates can differ in intrinsics. This is, I think, no more surprising than the claim that microphysical duplicates (in the sense of that term defined in section 2) can differ in consciousness, but this is also a crucial part of the account I wish to advocate. Moreover, the duplication account of intrinsicality is rather problematic (cf. Bader 2013), and so questions arise about just how costly it is in general to deny that Lewisian duplicates never differ in intrinsics. Second, it isn't clear that we must grant that Mary and Martha-Minus are Lewisian duplicates in the first place. Indeed, if consciousness itself is a perfectly natural property, as it is not implausible to think, then Mary and Martha-Minus will not be Lewisian duplicates due to the difference in consciousness between them.
} 
to the instantiation of consciousness only indirectly, namely, insofar as personhood is a condition on consciousness yet personhood involves maximality constraints. ${ }^{3 \mathrm{I}}$

\section{Conclusion}

Thus, we have seen that it is possible to accept Merricks' argument against (MS) without having to grant the problematic consequences involving consciousness that it seems to imply. If Merricks' argument against (MS) is sound, then microphysical duplicates can differ with respect to the intrinsic property of consciousness. However, we can accept this consistently with accepting (MG), the thesis that the intrinsic properties of complex objects are grounded in intrinsic microphysical properties. On the proposed view, when a person is conscious, she is conscious solely in virtue of instantiating certain intrinsic microphysical properties. However, this grounding relation holds only given that the person is a certain kind of thing. Any person-part that is a microphysical duplicate of that person, therefore, while instantiating those same (conditionally) consciousness-making microphysical properties, will not be conscious for that reason, whereby this is because the person-part fails to meet the necessary background condition of being the right kind of object.

On this view, consciousness is no longer mysterious. The consciousness facts are fully grounded in underlying microphysical facts. And differences in consciousness between persons and large person-parts are explicable rather than being brute. Moreover, unlike extant reactions to Merrick's case against (MS), the account developed here does not force us to reject our intuitive conception of consciousness as intrinsic, or to deny that human persons have large proper parts. The account offered here, therefore, has a significant advantage over extant replies to Merricks' argument. What is correct about that argument is respected, but the problematic consequences that these accounts imply are avoided at the same time. ${ }^{32}$

\section{References}

Audi, P. (201 2) 'A Clarification and Defense of the Notion of Grounding', Metaphysical Grounding: Understanding the Structure of Reality, (eds.) Correia, F. \& Schnieder, B. (Cambridge University Press): IoI-I 2 I.

\footnotetext{
${ }^{31}$ Sider (2003) would argue that this view sidesteps the irrelevant determiner objection insofar as it recognises a genuinely intrinsic property of consciousness*, which is just like consciousness except that it is not maximal. Unfortunately, however, this view leads to an analogous overpopulation problem, insofar as we end up with the result that each human person contains a mighty host of conscious* beings within their borders. Cf. Bader (manuscript-a); Merricks (200I, 2003).

${ }^{32}$ Note also that by avoiding the mighty host of conscious beings, we manage to avoid one important version of Mark Johnston's 'personite problem', namely, the version that would arise if it were shown, via Merricks' initial line of reasoning, that each of us contains a mighty host of conscious proper parts. That said, it is also important to note that the essence-based version of the problem, relying on the premise that all available essences are in fact instantiated (cf. Chihara I994), remains, as does the version that arises naturally from a temporal parts framework. Likewise, the similar problems realised in Unger $(2004,2006)$ remain as well, since these are motivated by the considerations that generate the 'problem of the many', and hence demand a separate treatment.
} 
Ayers, M. R. (1969) 'Perception and Action', Royal Institute of Philosophy Supplement, 3: 9I-Io6.

BADER, R. M. (2013) 'Towards a Hyperintensional Theory of Intrinsicality', Journal of Philosophy, I Iо (Iо): 525- 563.

Bader, R. M. (2015) 'Conditions, Modifiers, Holism', in Weighing Reasons, Lord. E. \& Maguire, B. (eds), (Oxford: Oxford University Press): 27-55.

Bader, R. M. (2017) 'The Grounding Argument against Non-reductive Moral Realism', in Oxford Studies in Meta-Ethics, I2, Chapter 5, (Oxford: Oxford University Press): 107-I 33 .

BADER, R. M. (manuscript-a) 'Maximality and Consciousness', manuscript draft.

BADER, R. M. (manuscript-b) 'Conditional Grounding', manuscript draft.

Burke, M. B. (2003) 'Is My head A Person?' in On Human Persons K. Petrus (ed.), Frankfurt: Ontos-Verlag, I07-I 25.

Chinara, C. S. (I994) 'The Many Persons Problem', Philosophical Studies, 76 (I): 45-49,

Dancy, J. (2004) Ethics Without Principles. Oxford: Clarendon Press.

Dasgupta, S. (20 I4) 'Metaphysical Rationalism', Nô̂s, 50 (2): 379-4I8.

deRossett, L. (20 io) 'Getting Priority Straight', Philosophical Studies, I49 (I): $73-97$.

Dorr, C. (2003) 'Merricks on the Existence of Human Organisms', Philosophy and Phenomenological Research, 67 (3): 7 I I -7 I 8.

Dunn, J. M. (1990) 'Relevant Predication 2: Intrinsic Properties and Internal ReLations', Philosophical Studies 60 (3): I77-206.

Epstein, B. (20 I 5) The Ant Trap: Rebuilding the Foundations of the Social Sciences, (Oxford: Oxford University Press).

Fine, K. (2008) 'Coincidence and Form', Proceeds of the Aristotelian Society 82 (I): IOI-IO8.

Fine, K. (20I2) 'Guide to Ground', in Metaphysical Grounding: Understanding the Structure of Reality, (eds.) Correia, F. \& Schnieder, B. (Cambridge: Cambridge University Press): $37-80$

Jones, N. K. (2010) Too Many Cats: The Problem of the Many and the Metaphysics of Vagueness, PhD Thesis, University of Birkbeck. 
Gilmore, C. (2010) 'Sider on the inheritance of intrinsicality', Philosophical Studies, I5 I (2): I77-I97.

Hawley, K. (1998) 'Merricks on Whether Being Conscious is Intrinsic' Mind, Io7 (428): $84 \mathrm{I}-843$.

Hawthorne, J. (2006) 'Why Humeans Are Out of Their Minds', in his Metaphysical Essays, Oxford University Press.

Horgan, T. E. (I993) 'From Supervenience to Superdupervenience: Meeting the Demands of a Material World' Mind I02 (408): 555- 586.

Humberstone, I. L. (1996) 'Intrinsic/Extrinsic', Synthese Io8 (2): 205-267.

Johnston, M. (2016) 'The Personite Problem: Should Practical Reason Be Tabled?' Noûs, 50 (4): I-28.

KIm, J. (I993) 'Epiphenomenal and Supervenient Causation', in his Supervenience and Mind: Selected Philosophical Essays, Cambridge University Press.

Kovacs, D. M. (2010) 'Is There a Conservative Solution to the Many Thinkers Problem?' Ratio 23 (3): 275-290.

Moran, A. (2018) 'Kind-Dependent Grounding', Analytic Philosophy, 59 (3): $359-390$.

Moran, A. (manuscript) 'Pluralism, Alternate Composition Cases, and Conditional Grounding', to appear in Objects and Properties, (eds.) Moran, A. \& Rossi, C., under review with Oxford University Press.

Merricks, T. (I998a) 'Against the Doctrine of Microphysical Supervenience', Mind, I07 (425): 59-7I.

Merricks, T. (I998b) 'On Whether Being Conscious is Intrinsic', Mind, Io7 (428): $845-846$.

Merricks, T. (200I) Objects and Persons. (Oxford: Oxford University Press).

Merricks, T. (2003) 'Maximality and Consciousness', Philosophy and Phenomenological Research 66 (I): I 50-I 58.

Oderberg, D. S. (201 I) 'Essence and Properties', Erkenntnis, 75 (I) 85-i I I.

Olson, E. T. (I995) 'Why I Have No Hands', Theoria, 6I (2): I 82-I 97.

Robinson, H. (2006). 'Personal Identity' in Mind and its Place in Nature (eds.)

Batthyany, A. \& Elitzur, A. Frankfurt, Ontos. 
Rosen, G. (2010) 'Metaphysical Dependence: Grounding and Reduction', in Hale, B. and Hoffmann, A. (eds.) Modality: Metaphysics, Logic and Epistemology, (Oxford: Oxford University Press): I09-I36.

Rosen, G. (2015) 'Real Definition', Analytic Philosophy, 56 (3) pp. I89-209.

Schaffer, J. (2009) 'On What Grounds What', in Metametaphysics, Chalmers, D. Manley, D. and Wasserman, R. (eds), Oxford University Press: 347-383.

Schaffer, J. (2017) 'The Ground Between the Gaps', Philosophers' Imprint I7: I26

Shoemaker, S. (2008) 'Persons, Animals, and Identity', Synthese, I62: 3 I 3-324.

Sider, T. (200I) 'Maximality and Intrinsic Properties', Philosophy and Phenomenological Research, 63 (2) 357-364.

Sider, T. (2003) 'Maximality and Microphysical Supervenience' Philosophy and Phenomenological Research, 66 (I) I39-I49.

Sider, T. (2020) The Tools of Metaphysics, (Oxford: Oxford University Press).

Unger, P. K. (2004) 'The Mental Problems of the Many' Oxford Studies in Metaphysics, Vol. I. Zimmerman, D. W. (ed.), (Oxford: Clarendon Press).

Unger, P. K. (2006) All the Power in the World, (Oxford: Oxford University Press). van Inwagen, P. (1981) 'The Doctrine Of Arbitrary Undetached Parts', Pacific Philosophical Quarterly 62 (2): I23-I37.

Wilsch, T. (2015) 'The Nomological Account of Ground', Philosophical Studies, I72: 3293-33I2.

Wiggins, D. (200I) Sameness and Substance Renewed, (Cambridge: Cambridge University Press). 